\title{
Influence of hydrothermal fluids enriched in As and F on the chemistry of groundwaters of the Duero Basin, Spain
}

\author{
E. Giménez-Forcada ${ }^{1}$, S. Timón-Sánchez ${ }^{1} \&$ M. Vega-Alegre ${ }^{2}$ \\ ${ }^{1}$ Instituto Geológico y Minero de España - IGME, Salamanca, Spain \\ ${ }^{2}$ Departamento de Química Analitica, Universidad de Valladolid - UVA, Valladolid, Spain
}

\begin{abstract}
Chemical and isotopic data of groundwaters from the south edge of the Duero Basin have been interpreted by multivariate statistical analysis including HCA and PCA. The results suggest that waters enriched in arsenic, fluoride and other associated trace elements are alkaline $\mathrm{Na}-\mathrm{HCO}_{3}$ cold-hydrothermal waters, flowing through main faults of the basement.
\end{abstract}

\section{INTRODUCTION}

In some areas of the southern area of the Duero Basin (DB), Spain, naturally occurring arsenic and associated trace elements are present in concentrations exceeding the limits established for drinkable water. The study area is located in the Duero Basin where Cenozoic sediments from the basin contrast with the metasedimentary and igneous rocks of the Spanish Central System (SCS) (Fig. 1).

In this range, As and $F$ are present in several rock-forming minerals from the crystalline bedrock. Arsenic is identified in sulfides (arsenopyrite), oxides (magnetite, ilmenite) and ferromagnesian silicates (olivine, pyroxene). Meanwhile, fluorine occurs in primary minerals as biotites, amphiboles, topaz and apatite. Both elements and other trace elements (Mo, $\mathrm{V}, \mathrm{Cr}$ and $\mathrm{U}$ ) constitute a suite of incompatible elements, which have difficulty in entering lattice sites of the minerals during the fractional crystallization of magma, and therefore are concentrated in the fluid phase.

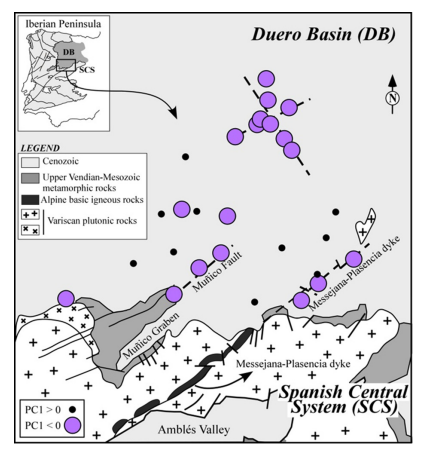

Figure 1. Location of the study area and distribution of PC1 scores.
The aim of this research is to gain knowledge of the geological environment controlling As and $\mathrm{F}$ contents in groundwaters of the south edge of the $\mathrm{DB}$, using multivariate statistical tools as Hierarchical Cluster Analyses (HCA) and Principal Components Analyses (PCA) for data interpretation.

\section{METHODS}

Twenty-one physico-chemical parameters, including temperature, $\mathrm{pH}$, electrical conductivity, redox potential, alkalinity, major anions and cations, natural isotopes and trace elements (As and F, but also $\mathrm{Cr}, \mathrm{Mo}, \mathrm{V}$ and $\mathrm{U}$ ), were determined in 34 groundwater samples collected from springs, wells and boreholes located in the study area (Avila province, Spain).

Water temperature, $\mathrm{pH}$, electrical conductivity (EC, $25^{\circ} \mathrm{C}$ ), and oxidation-reduction potential, ORP, were recorded on site. The ORP measurements were corrected for temperature and referenced to the SHE potential. Groundwater samples were filtered $(0.45 \mu \mathrm{m})$ in situ into polyethylene bottles. Those collected for cation analysis were acidified to $1 \% \mathrm{v} / \mathrm{v}$ with $\mathrm{HNO}_{3}(65 \%)$. Major anions and cations and trace elements were determined in the IGME laboratories by standard methods described elsewhere (GiménezForcada \& Smedley, 2014). Electrical charge imbalances were, in all cases, less than $3 \%$.

\section{RESULTS AND DISCUSSION}

The HFE-Diagram (Fig. 2) shows that samples with the highest concentrations in arsenic and fluoride correspond mainly to $\mathrm{Na}-\mathrm{HCO}_{3}$ waters.

Correlations of As with $\mathrm{F}$ and other hydrochemical variables were uncovered by HCA and PCA. HCA dendrogram shows two main families of variables (Fig. 3). One linked to major chemistry and those associated 


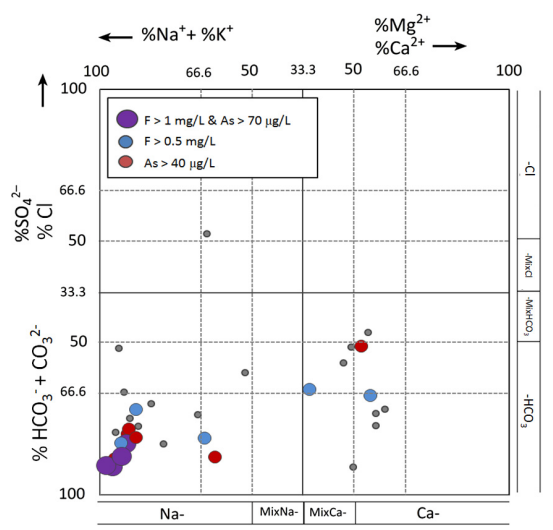

Figure 2. Representation of water samples in the HFE diagram (Giménez-Forcada \& Sánchez 2014), modified.

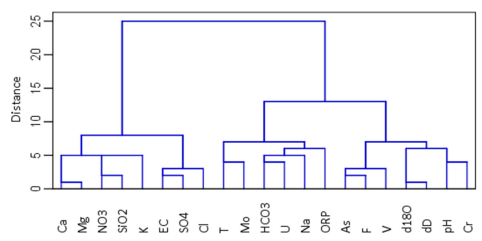

Figure 3. Dendrogram of chemical parameters obtained by HCA using the Ward linkage method.

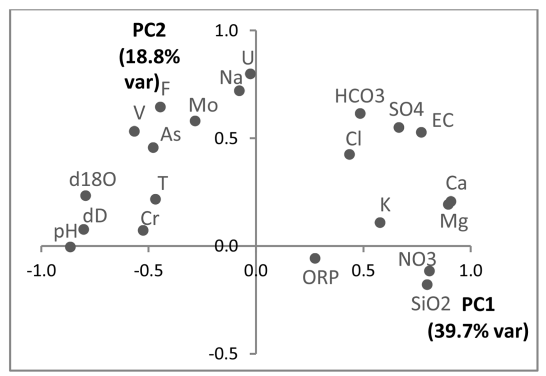

Figure 4. Loadings of the first two principal components obtained by PCA.

with $\mathrm{NaHCO}_{3}$ flows. PCA corroborates this association (Fig. 4). In fact, the first principal component, PC1 (which explains the $39.7 \%$ of variance) differences clearly the two main groups referred. These correlations suggest that there are alkaline $\mathrm{Na}-\mathrm{HCO}_{3}$ water flows feeding the basin. These waters, enriched in As, $\mathrm{F}, \mathrm{V}, \mathrm{Cr}, \mathrm{U}$ and $\mathrm{Mo}$ are characterized by a moderate temperature (cold-hydrothermal waters, $18^{\circ} \mathrm{C}-19^{\circ} \mathrm{C}$ ) and a singular signature of $\delta^{18} \mathrm{O}$ and $\delta^{2} \mathrm{H}$ (the most negative values of all both parameters).

The correlation between As and other trace elements suggests they have similar geogenic sources and are mobile under similar hydrogeochemical conditions. These sources include igneous-metamorphic bedrocks, mineral occurrences as well as geothermal fluids.
Scores of samples on $\mathrm{PC} 1$ have been represented in Figure 4 . The highest values are associated to relevant faults and their prolongation in the basin, showing a distribution of As, F and other trace elements controlled by structural features.

Previous works in the area have established the structural control of As distribution in $\mathrm{DB}$, and the correspondence of high contents of F, B and Mo with the highest concentration of As in alkaline $\mathrm{Na}-\mathrm{HCO}_{3}$ groundwaters (Giménez-Forcada \& Smedley, 2014).

Fluids flowing through major faults of the DB basement could be a relevant source of As in the study area. Therefore, it seems likely that the occurrence of As and associated trace elements derives at least partially from enriched deep hydrothermal fluids. Arsenic associated with geothermal waters has been reported in several parts of the world (Smedley \& Kinniburgh, 2002), and $F$ is recognized as a mobile element under high-temperature conditions and is abundant in hydrothermal solutions (Edmunds \& Smedley, 2013).

Without neglecting other sources and processes, the influence of cold-hydrothermal waters enriched in several trace elements and associated with the fissured aquifers from SCS, which in turn form the basement of the DB, could be relevant.

\section{CONCLUSIONS}

The high concentrations of As and $\mathrm{F}$ in groundwaters from the DB south bank could be explained considering inputs of hydrothermal fluids flowing through main faults of the basement. This process does not exclude other possible sources as water-rock interaction processes.

\section{ACKNOWLEDGEMENTS}

This work was supported by the Geological Survey of Spain (IGME). HidroGeoTox (Research Project Ref. IGME-2303) and by the Junta de Castilla y León (Research Project Ref. VA291U14/Ref. IGME $2474-$ As Cega).

\section{REFERENCES}

Edmunds, W.M. \& Smedley, P.L. 2013. Fluoride in natural waters. In: O. Selinus, (ed.) Essentials of Medical Geology, Second Edition. Springer, 311-336p.

Giménez-Forcada, E. \& Sánchez San Román, F.J. 2014. An excel macro to plot the HFE-Diagram to identify sea water intrusion phases. Groundwater 53(5): 819-824.

Giménez-Forcada, E. \& Smedley, P.L. 2014. Geological factors controlling occurrence and distribution of arsenic in groundwaters from the southern margin of the Duero Basin, Spain. Environ. Geochem. Hlth. 36(6):1029-1047.

Smedley, P.L. \& Kinniburgh, D.G. 2002. A review of the source, behaviour distribution of arsenic in natural waters. Appl. Geochem. 17: 517-568. 